\title{
An Interview with David Teece, a Practicing Business Intellectual
}

\author{
Jon Eckhardt (University of Wisconsin-Madison)
}

KEYWORDS: Entrepreneurship, Research Methods, Leadership, Startups.

Professor David Teece is one of the impactful business scholars of his generation. His research has been cited over 128,474 times according to Google Scholar. His work is required reading for Ph.D. students all over the world.

A Professor in Global Business at the Haas School of Business at University of California - Berkeley, Teece is unique in that he is also a successful entrepreneur who has started several companies. In 1988, while a Berkeley professor, he started The Law and Economics Consulting Group, Inc. (LECG). He is also the co-founder of Berkeley Research Group (BRG), a consultancy that is a leading global strategic advisory and expert consulting firm to Fortune 500 corporations, financial institutions, government agencies, major law firms and regulatory bodies around the world.

Many business schools frown on their professors taking on such entrepreneurship and consulting practices because they fear it will detract from the professor's research duties. However, in other fields -medicine, law, and engineering -- practice is seen as so central to the advancement of science at some institutions that the two are closely integrated. The work of David Teece provides us with a window into the insights and capabilities he was able to generate as a business professor who lives in the world of practice and science. This role is called "translational research" and its core belief is that scholarship can be advanced by people who are both scholars and also practitioners in a particular domain.

Teece recently sat down with us for a wide-ranging interview about how the academic and business worlds can be more closely connected. He spoke about the need for translational research, which is informed by actual business problems and generates insights that help business executives make decisions that are informed by science and facts. Teece's perspectives are important to both academics and entrepreneurs.

\section{A practicing business Intellectual Jon Eckhardt}

We have a distinguished scholar with us today, David Teece. I'm sure that you have all read David's work. The topic today that we're going to talk about, and the reason why l've invited David to have a conversation with us, is about translational research in business. The basic idea of translational research, is that scholarship can be advanced by people who are both scholars and also practitioners in a particular domain.

Translational Science is most prevalent in the academy in medical schools where some doctors treat patients and also run basic science labs. These individuals-often termed physician-scientists- make fundamental contributors to our understanding of basic science in fields like medicine, human physiology, and physiology. Translational science is almost unheard of in business schools. In business schools, faculty are either researchers or business people. Few are both.

So David Teece, as we're going to learn about today, is a rare individual in a business school. He has built an amazing career making large academic contributions to our understanding of, at least for me, entrepreneurship and management more broadly, but also has had quite a career as an entrepreneur and business person himself.

Before I get into that I would like to just quickly mention that James Beal's voice that you hear in the background is part of the infrastructure with a group called Entrepreneurship \& Innovation Exchange. This is a new peer reviewed website devoted towards making the best science in entrepreneurship more accessible to entrepreneurs, but then also trying to turn the engine a 
little bit and try to get academics to engage in entrepreneurship and business themselves, for the purpose of making their research hopefully more useful to rising entrepreneurs.

EIX was started by James Wetherbe, who has made a career as an academic and business person in information technology, and Dick Schulze. Dick is the founder of Best Buy. An amazing individual who not only built his company, but who also boomed in the era of the big stores. Best Buy has survived at least two significant major threats to his business, including the arrival of Internet retail and Amazon.com. If you look, Best Buy is doing quite well. Dick is quite an amazing business person, and he has many insights to offer academics.

I'll start with this quote from an article about your career in The Pennsylvania Gazette, the University of Pennsylvania's alumni magazine. It says, "deep down really what I am is a practicing business intellectual, and that is almost an oxymoron." We'd love to learn how that came to happen, and how you do it, how you manage the different demands on your time as an academic and also as a business person. So, if you could start with sharing with us your first business act maybe, what led you down the path.

\section{David Teece}

I will start from graduate school, but I could go back earlier than that. In graduate school I was an active consultant, at least in my final year. Of course, I kept that very quiet because it wasn't necessarily looked upon well by the faculty. I suppose I was a little bit ambivalent myself about whether l'd be an academic or something else.

I got persuaded in graduate school that if in doubt, one should teach. So that was a pretty good idea. The university was always a great place, always loved the university, but always felt if I needed to I could leave it and go somewhere else.

Having said that and getting into the university environment I found it was possible to do both, but one had to be very comfortable about doing both, and one had to be very committed to working and fulfilling criteria (if you will) on both sides of the line simultaneously. Which means, you really got two jobs, not just one.

I think as a faculty member you have a duty to the university to do research and teaching. There is a commitment that is being made both ways and it needs to be honored. So, if you're going to do stuff on the outside, and I think it's great to do stuff on the outside, then it should come on top of and not as a substitute for one's everyday responsibilities. And there's unquestionably lots of complementarities and positive benefits from doing the two, but it's easy to get sucked out of the academic world and into the world of the practitioner because it's actually hard to live on the cusp, as I have, for 35 years.

\section{Graduate School Jon Eckhardt}

You said you did some consulting when you were in grad school, did that show up on your dissertation anywhere or change how you were learning as you tearing through the literature at that time?

\section{David Teece}

No, it didn't. It showed up soon thereafter. But what did show up in my thesis was I went out and did a lot of field research; I interviewed over 100 execs and I would say that was an incredibly valuable experience to me. I wouldn't have been able to walk into teach MBAs if I hadn't had detailed conversations with 100 execs and visited over 30 companies.

When I say detailed conversations, it was part of my thesis in trying to get data and a good understanding of their business. So I think it's very good to have exposure to not only the great academic minds, but if you're interested in business you've got to have deep exposure to the people making business decisions.

\section{Jon Eckhardt}

When you were doing the consulting in grad school, what motivated you to do that?

\section{David Teece}

Well I got a lucky lift I think. I was at Penn and Oliver Williamson was a professor there and I was waiting for my advisor, who was Ed Mansfield, to read my thesis and I volunteered my time free of charge to Williamson as a research assistant, and I came to understand that at that time there were some really hot issues around the structure of the American Oil industry. People in industry had reached out to him because he was the expert on vertical integration. But it was clear he really didn't have much interest himself in getting into the details of the structure of the industry, and I was. 
So he gave me an entree there and I managed to sort of take his theoretical frameworks and use it in a dialogue with people in industry to help shape outcomes, private decisions as well as legislative and regulatory issues. So that was my lucky start. Oliver did give me a lead, otherwise I might never have gotten going in the way I did.

\section{The Challenge of Working in Academia and Business Jon Eckhardt}

Let's jump to your life as an early faculty member. What was that world like for you, and how did you at that stage stay exposed to business or did you set it aside for a while during that time?

\section{David Teece}

No, I was actually an active consultant. I wasn't starting businesses at that time, but I lived two lives. As you know, as a young untenured professor the presumption was you should be focused on research. It's not a bad presumption actually. I do think that there is a time up till tenure where maybe you should be reserved and somewhat limited in the amount of time you spend outside on consulting.

Notwithstanding that there are also petty academic jealousies and I was I think making a lot of money as a consultant. When I was a junior assistant professor, I was at Stanford at the time. I was making more money than most of the other faculty members by a long shot. I just kept it quiet because there would have been an immediate presumption that I wasn't a serious researcher. Maybe a little different these days, but it took me 10 or 15 years before I really revealed to any of my colleagues what I was doing on the outside for fear that it would actually be taken as a negative.

\section{Jon Eckhardt}

So you were kind of doing this in secret I guess, is what you're conveying. I have to share with you, and hopefully others will pipe in on this during the Q\&A, after I got tenure I looked around the building and found that there were a fair number of faculty in my building that had quite high citation counts. And as I got to know them better some actually had a fair amount of outside business activities.

I was quite fascinated by that because they also tend to be people who were quite effective academic administrators. They were often managing an activity in the school and they were known for being quite good at it.

When did you first decide to share with people and when did this become part of your story?

\section{David Teece}

When you say in secret, I mean I just wasn't talking about it. I wasn't trying to hide the fact that I was doing active consulting work, but I didn't want to rub it in the face of my colleagues.

Look, even throughout my entire career l've been very judicious. Not everybody on the faculty knows how to consult, and there are enough petty jealousies running around in the academic environment that I thought we didn't need another. The last thing I want to do is make anybody feel uncomfortable that they can't do both research and consulting. So, l've kept it very, very low key to this day.

Although obviously with the Berkeley Research Group and with taking a couple companies public, I'm no longer in the shadows. But at the same time, when I'm on campus I don't typically run around talking about that. I focus on the business of the university, which is research and teaching.

Obviously what l've learned on the outside flows back into my teaching, and into my research, but I tend to underplay what I'm doing on the outside when I'm on campus, because campus is a full-time, well I'm a $50 \%$-time professor, but it's a consuming world. Not an all-consuming world, but it does require a lot of time and effort to discharge your professorial job the right way.

\section{The Synergy of Practice and Science Jon Eckhardt}

So one thing that I found interesting in the medical schools is they take it one additional step where practicing as well as researching is part of their responsibility for the physician-scientists. When they submit their annual report they include their clinical activities are part of their contribution to the University. Now part of that is because in most cases the hospital has had some kind of close institutional affiliation with the university, and in some cases they are even the same entity. But at the same time, they learned, I 
believe in the 1970s, that they had to integrate the practitioner enterprise with their scientific enterprise by building a type of professor that were basically doing both-practicing medicine and conducting research. Can you share with us your thoughts on how your business activity has related to your science?

\section{David Teece}

Well, let me go back to the stem of your question because it's a very interesting one. At the University of California Berkeley as in most universities, there are four criteria of faculty advancement: research, teaching, professional service and public service. One can never put consulting into that category. But l've had some conversations with some very senior officials at Berkeley recently with respect to expanding the four criteria to indicate impact, not just on the profession, but on the broader world. And that if you wrote in the words "impact" into advancement criterion, it would open the doors for people, particularly in technical fields that have great ideas, to actually move those forward to new ventures and have that actually be something that is properly recognized by the university.

I've actually written a paper recently, it's not published, but I wrote it for my own university to help the vice chancellor for research move forward the agenda for making it more of a normal and desired thing for faculty to engage in entrepreneurial activities. In many great research universities there is still ambivalence about it, and for some good reasons; but I do think if you've got important research there is an obligation to have impact with it if in fact it can benefit society.

\section{The First Startup Jon Eckhardt}

Can we discuss LECG as an example? This is a company that you helped start. Can you share with the audience why you decided to start LECG and what that company does?

\section{David Teece}

LECG was my first sort of, well it wasn't the very first, but it was the first significant professional services firm I founded. I had been very active at creating programs inside the university and raising money for the university and quite frankly, I got a little bit fed up because I would constantly start programs, raise the money for it, and then the Dean's office would love the programs, but no one would sort of reach out to help, and I would be rewarded by the obligation to continue to raise money for many of the school programs.

I was doing all the entrepreneurial stuff, making good things happen, which I was pleased to do, but after a while I realized I had the ability to start things and to grow them. So, I thought maybe I should do one outside for fun and for financial benefit, because I was clearly over-performing inside the university and not getting any thanks for it. So I suppose one part of me said, ok if there's no thanks from inside l'll do something from the outside where at least l'll have some significant impact on the profession and also it will be an opportunity to create wealth, not just for myself, but for faculty and other people that were affiliated with it. And the truth of the matter is I made some of my colleagues pretty rich.

\section{Jon Eckhardt}

The work that LECG was doing was economic consulting, right? Such as harnessing insights from economics to support legal cases?

\section{David Teece}

That's how LECG got started. It became quite diversified, but that's the starting point. With the Berkeley Research Group, which is a company that I started 8 years ago, likewise. Economics was a starting point but particularly in the case of BRG it's become very diversified beyond economics and embracing many different disciplines. In fact, it's got a strong academic patina, but it's a little more distant from the economic world than LECG was.

\section{Building Relevant Theory Jon Eckhardt}

To get back to the tie with science, perhaps an example from our medical school might be helpful to set the stage. At the UW hospital, a patient was seen who was ended up taking a large amount of Prozac. The doctor who reviewed the ECG was a translational scientist. The ECG was abnormal and this type of abnormality had never before been seen associated with high dosages of Prozac. He goes back to his lab and the short version of the story is he and a group of scientists discovered through basic science that Prozac was inactivating an electrical channel in the heart in a way that was not previously understood. They wrote a basic science paper about it but then right away had an impact on practice because the mechanism was understood.

Part of what got me involved in applied activities is I 
needed a mechanism to generate this type of insight. If you think back in your work, do you see these ties where you felt like you saw things that other academics didn't see, because instead of getting into your car every day and driving onto campus you get in your car on some days and you went to LECG or to BRG?

\section{David Teece}

No question. I'll take one area where I've done a fair amount of consulting and that is intellectual property. There are some models that have gotten currency in the academic world around hold up issues and royalty stacking. There is a whole litany of theories that are really driven by the desire of academics to build elegant little models. But they have almost no connection to the real world.

So, there is no doubt that being active in the world of advisory services and expert consulting gives you a keen sense of the issues that are real and those that are phony or theoretical. I would say the real benefit to me is, your Prozac story is a very specific one, I would say that generally the impact has been in my case much more of a general kind. When I'm reading research papers, that which is nonsense is sort of fairly clear to me right away. Experience gives me a great filter. I know when I see a great paper that has some amount of theory in it, but it is nevertheless written by someone who actually knows what's going on in the world.

So, I would say there are multiple filters that the exposure to the real world gives you on the academic literature and I think in my case that filter has helped me realize what in the academic world is important and what research is really valuable, and also the other way around. Knowing what good research is and knowing some of the fundamental ideas that have come from the academic world that have been tried and tested helps me in business.

That really helps me a lot in managing, we've got 1,200 people in BRG and when you come to sticky points, I've got my board of directors, I've got the people I go to for advice, but I'm implicitly tapping into the academic literature every day when making business decisions. When I say I'm implicitly tapping into it, I mean I don't need to go hire a consultant for a lot of key issues, and moreover, I can make quick decisions because just about everything you see in the business world has been seen somewhere else and there's some academic literature on it that I am generally familiar with.
So, while context still matters, most execs only have limited experience. They've got experience of the 1, or 2 or 3 companies they've been in, whereas in the academic world if you've read widely and looked at both empirical and theoretical work you've got a lot more contextual appreciation for what's going on. So, I definitely see a two-way street there. There is no question in my mind that I have had a lot of benefit from the academic literature. The literature helps me make better business decisions.

\section{Balancing Academia and Business Jon Eckhardt}

How do you manage the practicalities of having these two careers?

\section{David Teece}

It's a very good question. As I said earlier on, really you kind of have to let go of some elements of the academic life without letting down your institution or your colleagues. It does require you to work a lot harder and put in a lot more hours, and maybe if you're smarter than I am you can do it in less hours, but I ended up having a fairly heavy workload. Now I could have quit the university, but I've chosen not to. I did choose to go down to $50 \%$ time and I'm so fortunate that the University of CA allowed me to do that. Most campuses won't, and for good reason; you don't want everybody to be part time.

So what you see in the academic world, at least in the business school at Berkeley, you have two faculties these days. There is a professional faculty, which are adjuncts and consulting professors or whatever you call them; then there is the regular faculty. The professional faculty of course are more involved on the outside than on the inside. The regular faculty may be entirely academic, or they may have some kind of consulting gig going on, but they're not building and running companies.

I think this mixed model does make a fair amount of sense. I think as a tenured regular faculty member it is hard but beneficial to work both areas simultaneously.

\section{Jon Eckhardt}

Do you have any particular strategies that enabled you to survive, or earn the respect of your colleagues who are more skeptical perhaps? I think one piece of advice that l've picked up already is that you must remain active in the academic world. You must be writing 
research papers and everything else as part of the gig. Are there other pieces of advice that you might have for folks that want to go down the same kind of path?

\section{David Teece}

Yes, I really haven't cared what other people think. If I did I probably would have stopped a long time ago and not done what l've done. The motivation is to do something great, build a new type of organization. If you just go replicate what everyone else has done it will not be exciting. l've been able to find purpose from building organizations that are different.

What I like to think I've done with BRG is bring the Silicon Valley model of business organization to professional services. There's been almost no management innovation in the world for about 150 years. You've got the M-form organization and division. You've got a few significant innovations, but it's quite pathetic how little innovation is actually taking place. Firms are run at the fundamental level today pretty much the way they were 50 years ago or 100 years ago.

What we've created at the Berkeley Research Group is a very metrics-driven organization that is way more decentralized. It's more of an inverted hierarchy that empowers top talent and blows up the politics of pay. I just love doing things that are unorthodox. Having an understanding of the literature enables you to know what orthodox is and what orthodox isn't.

I'll give you a case in point. The Google CEO Eric Schmidt and Jonathan Rosenberg wrote a great book on Google and they were kind enough to let me review that book. My 10 pages of comments, in essence said, listen: a number of things that you think you've done that are new are actually 50 to 100 years old.

So people in industry often do things that are new to them but they don't realize it's actually something that's been done before. Maybe they do it a little differently, but if they do it a little bit differently because they don't know what was done before they're not even able to explain very well what the management innovation is that they have achieved.

I think being an academic enables you to be innovative about business organization, at least since that is my area of interest, that is one thing I think I've done. Now there is always a huge regression to the mean and there are always forces that push you back. Every organization that starts off being different has a lot of pressure to conform to what everybody else does, particularly if you go public and you've got all the governance apparatus that is required by law that gets imposed on top. So it's actually hard to stand out.

\section{The Value of Academics to Business Jon Eckhardt}

We have time to take some questions from the online audience.

\section{Brent Goldfarb}

I have two questions. You can pick and choose what you're most interested in. The first is, when you're in the field do you see more short term-ism than you have in the past, say when you were starting your career 20-30 years ago.

Question two is, what do you think of the theory of disruption and more particularly, if you see things that are very well ingrained in decision maker's beliefs but may not have strong foundations, like they're convinced the first mover advantage when we know it's much more nuanced than that. Do you find it very difficult to change people's minds on those?

\section{David Teece}

I'll deal with the first question on short term-ism. I've been studying this a little bit over the years and I've come to the firm conclusion that short termism is driven by our system of corporate governance, particularly shareholder activism. Most of you may be aware of the work I've done on dynamic capabilities It's very hard to take the long view and invest for the future, which is what dynamic capabilities requires, when you've got shareholder activists that will come and shoot you down if those investments are going to cost you with respect to the next two quarters of earnings.

As we're giving more and more legal purchase if you will to the activist community, it's very hard for a CEO to hold onto his job and do the right thing. The only people that can hold onto their jobs are those that own a big chunk of stock, or they are founders, or they're running very complex companies that the activists really can't get to understand and can't make any credible threat of ever taking over. So, I think the governance structure more than anything is what's at fault. Yeah, I think it has 
gotten worse.

On disruption, it's quite pathetic to tell you the truth how little some executives appreciate what is common knowledge in the academic world. They'll believe the first mover advantage story, or they'll develop beliefs based on prior experience, whereas I think coming from the academic world you tend to have a way more nuanced view.

One of the things that l've done the last 2-3 years is I've actually done a little bit of mentoring of CEOs and it's quite hard to jump into an organization that is fast moving and has a lot of history and make a difference, and to be "spot on" in your advice because you just don't know the facts of the situation.

But at the same time, you can have impact, if someone has an open mind and is willing to listen. Let's take the automobile industry today. If you listen to the guys in Silicon Valley, Tesla and Apple and Google are going to bowl over the traditional companies and they'll all be gone in five years. I personally don't think that is true at all. Why isn't it true? Well if you actually look at history you'll find that when there are complicated systems involved it takes a long time to overturn the existing order.

So just being aware of diffusion studies and being aware of the way in which industry does evolve enables you to sometimes be more realistic and give the executives the benefit of that much broader experience space that's implicit in the academic literature. You can advise where the technology is likely to take root initially, and the segments where it will take a long time.

The academic literature is quite frankly impenetrable to execs and they don't read anyway. They don't have time to read. Accordingly, there is a huge translational problem here. Few people understand the academic literature very well, and it's not enough to know just one piece of it. You've got to know a lot of different fields to be a useful advisor in the executive world, but I think there is a very valuable role that academics can have. They have a broad base of understanding that they can bring to industry and to executives and to government too for that matter. They can really add a lot of value and have a lot of good positive social and economic impact.

\section{Silos can limit research Martin Ganco}

I'm Jon's colleague at the University of Wisconsin. Thank you very much for a very interesting and insightful discussion. I have a question about, going back to research and strategy. David, what are some areas that you find may be interesting or promising? A higher-level question, what are some areas that you find problematic? What is your view of that current research in strategy?

\section{David Teece}

Well I was just at the strategic management society meetings in Houston. I think what has happened to the field of strategy, which used to be an integrative field, is that it has just collapsed into a bunch of silos like most other fields have. What's missing in the academic world is faculty who both do research that is highly integrative and who think in an integrated way.

One of my own discoveries recently that I just happened to chance upon was an early issue of Management Science where there was an aspiration in the 1950's and 60's to sort of develop a general theory and systems theory. I remember when I was in graduate school at Penn there was this guy Ross Ackoff running around, and at Berkeley there was a guy called C. West Churchman. These brilliant scholars were trying to create a system theory, an integrative view of not just management but maybe of the social sciences.

I think what happened since the Gordon and Howell report in 1950 and the push for business schools to focus on the disciplines is that we've gone from business schools that were much too practitioneroriented to business schools that are discipline focused, which I think is great, but it becomes so narrow in the individual disciplines that what is missing today is a holistic perspective.

And of course, what I like to think that I have done with dynamic capabilities, and I'm starting to articulate it this way now, is create a workable systems theory of management because it looks at everything from the role of business models, intellectual property, strategy itself, organizational change on business performance. You've got all of these topics taught in business schools and in economics department but there is nobody pulling it together. If academics are crossing boundaries they're crossing maybe one at a time. But if you're in the executive suite you're crossing them 10 and 20 at a time. We are impoverished in the academic world in terms of rich frameworks that enable you to 
integrate ideas.

So increasingly academic research is becoming a very narrow rifle shot into one particular issue, which is a nice contribution, but I think to really have impact with academic research and to be useful to executives we've all got to become much more interdisciplinary. Given that execs don't have the time to read across fields one of the key roles that is left for us as academics is to read and integrate and synthesize and only then can we be really helpful to executives.

\section{Martin Ganco}

I like that a lot and I agree. However, I think the incentives this time is sort of such that it promotes maybe the more compartmentalized silos.

\section{David Teece}

Let me address that by saying the following. The only reason that l've been able to do what l've done is because I haven't cared a wit about the incentive system in the university. If I cared about the incentive system my research would have been much narrower and I would have had a very different career, and one that would not have been as interesting.

I will say to all of you that are interested in having impact: you've got to go after something that you think is big and important and is beyond yourself and just go do it. Whether it's building something inside the university or beyond. If you pay attention to the micro details of the incentive structure, you'll blunt your pick for sure.

On the research side I think you have to have a good nose for important problems, and for fundamental problems. What is happening is that no one is looking at fundamental problems. They're trying to get a piece of research published. If you're trying to get a piece of research published rather than trying to address a fundamental problem you're not going to get very far. You may get something published but it's going to be a small blip.

Busting boundaries and busting orthodoxy, whether you're doing research or crossing the divide to do entrepreneurship at the same time, you've got to really do that. If you pay attention to the rules and regulations, well you have to pay attention to rules and regulations, but if you pay attention to the narrow incentive structure in front of you and people's attitudes you'll get stranded.

\section{Olubukunola Akinsanmi}

I'm a fourth year Ph.D. candidate at the University of Wisconsin-Madison. I was going to reference what you just mentioned about crossing boundaries and not staying siloed within one field, even within academia itself. Would you say that, maybe as a Ph.D. student, I should probably stay siloed for now?

\section{David Teece}

Yeah, here's the problem. The irony here is that one of the reasons for people being in silos is so that we can measure them. The academic world has to do its thing and objectively evaluate faculty research, and I think it's fine up until the point of tenure. Once tenured, I think you have an obligation, and the system has an obligation, to expect and demand more and to measure you differently.

The problem is that interdisciplinary research is really hard to measure, and there is a lot of bad interdisciplinary research out there. l've been respectful of the fact that universities have real problems. It's easy to say, look everybody is so narrow and all this disciplinary research is off base. And some of it is. I think most of it is.

But I also understand that there is a need to sort of test the mettle of people and see if they're actually good researchers. I don't expect, nor do I advise, untenured faculty to be too interdisciplinary; it's a risky game. But once you have tenure, then I think it's both an invitation and an obligation because no problem in the world is packaged into a nice little silo. Just about every important issue that I can think of crosses multiple boundaries.

\section{Bridging the divide between research and practice Michael Ciuchta}

I was working with Jon on this project so maybe it's a little heavy on my mind, but I was reading your Research Policy talking about platforms, and listening to you talk makes me think that, is this like a platform situation where you have research on one side and practitioners on the other? And is there potentially a role, and maybe this is what good centers do, where they actually facilitate that change across the platform? Is that a good way to think about it?

\section{David Teece}


Interesting insight. I never would have quite thought about it in those ways, but it's not just a matter of brokering and putting things together. I think we need good transitional research.

\section{Jon Eckhardt}

Translational research and that's the term they use in medicine. I don't really like it because it implies that someone is just explaining something from one domain to another instead of actually inventing and creating. But when they do it they are doing basic science research and they are bringing it into practice and they're taking practice and bringing it back into basic science research.

\section{David Teece}

I'm starting to warm up to it actually. You're right. On the medical side of course is clinical and theoretical and the two really join in a unique way. Your early example was a good one, but I think in business it's different. I was appointed the mentor to a top CEO by the board for a considerable period and what was I doing? I was doing that job of trying to translate academic research, not in terms of saying, "hey look I think you should go read this or do that." But the advice that I was giving was based on stuff that I understood reasonably well that he didn't really have any background in or a clue about.

To be translational requires that you actually be interdisciplinary and that you that you can communicate and work with practice. We haven't talked about that yet. But if you can't communicate in executive speak to executives you're not going to be a very good mentor or consultant.

And if you're going to create a company, I think you need to be able to communicate broadly with new employees. So, communication skills are very important, and networks are important too. That's the other thing that none of us have talked about, but in the academic world actually we are reasonably networked, at least many of us are. If you look at entrepreneurship one of the key prediction of startup success is people with good networks that know where to go to get the resources they need.

So many academics have that capability. In fact, what research has shown at Berkeley, or at the University of California System, is the best researchers are also the most active consultants and most active with startups, and they also bring money into the university. So, there's a subset of faculty that seem to be able to do everything quite well and do so to the benefit of the campus.

But then there is the long tail that don't do much. I suppose that is maybe the fact of life, but I just don't know. I think you're doing something good here by thinking in an intellectual way about how do you do this translational stuff well. Because it's sort of, as I started off earlier explaining it, it's sort of a little bit in the bushes. There really isn't the kind of dialogue that there should be around how to bridge practice and research even in business schools where you would think it's very natural. It's not just medicine that does it well, but it's architecture. Most good architects are also practicing. And in law too, there's a more natural pathway back and forth. Somehow, in academic business schools, we sort of got ourselves tied up in some silly knots.

\section{Jon Eckhardt}

I think engineering is another place where you see a fair amount of applied activity as well.

\section{David Teece}

And bio-sciences and chemistry too.

\section{Dynamic capabilities Rakoon Piyanontalee}

I'm Rakoon, also a Ph.D. student from the University of Wisconsin. My question is a little narrower. Specifically, how might you try to translate the concept of dynamic capabilities towards the individual level. By this I mean, looking at the workers, how would they adapt their skill sets in response to the changes in their work?

\section{David Teece}

Well, dynamic capabilities, to me at least, is focused more on the $\mathrm{C}$-suite. Of course, there are capabilities of a different kind that need to exist inside organizations, but dynamic capabilities are really about the resource allocation function of the top management team. Where are they placing their bets and why? How do they bring evolutionary fitness to bear by making sure that what companies produce is in tune with market needs? And in fact, go one step further to shape markets as well as to shape technologies.

l've in recent years talked about the different between ordinary, Sid Winter probably used this term first, operational and ordinary capabilities vs. dynamic. Both 
kinds of capabilities are necessary to get things done, but the ones that create competitive advantage are not the best practice stuff that we teach in school. Yes, you have to have that or have access to it, but real value creation and capture takes place through dynamic capabilities. And that requires this integrative set of skills at the organizational and individual level to sense, seize, and transform.

As I said earlier, it's sort of a general theory of how top management should see the entire strategic picture for the organization and it doesn't address the narrower training issues. But when you get to a decide that a company has to move in a very different direction to survive, then yes of course, the relevance of the individual skill set becomes salient. The lack of capabilities slow transformation down in the organization a heck of a lot.

\section{Linking scholars and policy Martin Ganco}

I was at SMS in Houston as well and on one of the panels there was discussion of strategy scholars in policy making. What are your thoughts? Again, I think one of the arguments was economists are very good at that, how come we're not, and what are the ways that we can be more engaged and what are some problems there? So, it's not only bridging scholars and managerial practice, but maybe bridging also scholars and policy.

\section{David Teece}

I've been thinking about that a lot lately. You say economists are good at it. They have managed to persuade the world that they're the ones that have the policy answers, but they're not as good at it as they think. That is why the system is so screwed up right now.

I think there is a huge opportunity. Let's take corporate governance. The strategy field does almost zippo in the field of governance today and so governance studies take place in law schools. I'd recommend you read, there is a great section about 20 years ago in the Harvard Business Review summarizing a debate between Alfred Chandler and Michael Jensen around leverage, debt, and managerial decision making.

The agency theory view, which most finance departments bought into, recommends taking away as much money as you can from the manager's purview, load the companies up with debt, get them to do stock buybacks, but don't for heaven's sake leave managers with any resources to allocate to new businesses because they might screw it up and hurt (short-term) earnings.

Chandler, of course, was on the other side saying that greatness in business is built through the astute allocation of resources and you've got to have managerial flexibility to allocate resources. The astute allocation of resources by management is the very essence of value creation, and value capture.

How many people from the field of strategy are having any impact on the field of governance today? Zero. Why is that? Because once again people are falling into silos, and actually in the case of strategy, ignoring the governance questions. Those scholars studying the role of the top management team, if they're not dealing with governance, they're not dealing with the real world.

What the top management team can do is very much a function of how the board of directors, operates: how it's composed, how it acts, and the constraints of the law. So, there is a huge opportunity I think. I am thinking about this in a very, very big way.

All international trade theory that sets up policies depending on simple Ricardian notions that are not informed by anything to do with business and how real business decisions get made, how technology gets transferred.

It's a huge opportunity. Once again, you just can't decide as a strategy scholar that somehow or another you're going to start to do public policy. You've got to make a ten-year investment in understanding some policy questions, be it governance issues, or be it other issues, before you can be effective in that.

\section{Jon Eckhardt}

We have about three minutes left. Would you like to share with us some closing remarks? The topic people are thinking seriously about is this translational model and how to execute it, let's say $10 \%$ as well as you have. Both as far as using their practice to inform their research and then having their research inform their practice. What closing advice do you have for us?

\section{David Teece}

Well first of all, I think it's great you are focusing on these issues. These are broad issues for universities 
today. The way the university is going to be fifty years from now is different from the way it was fifty years ago. There is a piece in the New Yorker 4-5 years ago saying, hey listen, Stanford is not a serious university anymore because it's so riddled with conflicts because all the faculty are out consulting on this, that, and the other thing, and have startups going.

In fact, if you look at MIT, Stanford, Berkeley, there is a lot of entrepreneurial activity going on. Ironically, this translational stuff is taking place with engineering, bioscience, chemistry and not much at all with the business school. The business schools have become sort of academic outposts, and in fact if you look at engineering schools like the one at Stanford, they've built another business school inside the engineering school because the GSB at Stanford is so irrelevant to anything to do with innovation, which is the essence of what the engineering school is interested in.

I think that what you're onto here could be part of breathing new life into what business schools do. We have to figure out how to do this translational research, or whatever you want to call it, to make it fit and get recognized as being legitimate inside the university and inside business schools. And maybe even though I told you my success was because I completely ignored the incentive system, I know that most people are not going to do that. So, we have to find ways to really recognize entrepreneurial activity that benefits the university; not all of it does but some of it does.

We have to find discriminating ways by which faculty engagement with the outside doesn't just benefit the individual faculty member but also benefits the students and benefits the entire campus. No one has threaded that needle. No one has written that down in a useful way yet. I think collectively, we need to do that over the next 5 years so that we can have engagement on the outside. There are some parameters -- not just around conflict of commitment issues, or conflict of interest issues -- but sort of guidelines around the kinds of research and the kinds of engagement that are really beneficial to the campus and to society. And if you can help your campus then I think that you will have made a major contribution.

\section{Jon Eckhardt}

Thank you very much David for joining us-very inspiring! 